\title{
O cenário do desejo amoroso: o locus amoenus em Propércio I.20
}

\section{The scenery of amorous desire: the locus amoenus in Propertius I.20}

Adir de Oliveira Fonseca Jr.

Universidade Estadual de Campinas (Unicamp), Campinas, São Paulo, Brasil. adir.ofjr@gmail.com

Resumo: O poema I.20 de Propércio é frequentemente apontado pelos críticos como uma composição complexa, ou mesmo obscura. Nessa elegia de 52 versos, Propércio, lidando com matéria pederástica, alude ao episódio do rapto de Hilas, e traça um paralelo entre o famoso mito e a atual situação vivenciada por Galo no plano amoroso. Ao fazer isso, Propércio recorre a diversos elementos típicos de um locus amoenus, de modo a descrever o lugar onde os eventos narrados transcorrem. $\mathrm{Na}$ verdade, uma análise atenta mostra como essa tópica também recebe um tratamento metapóetico, na medida em que certos vocábulos e imagens a ela associados parecem remeter diretamente ao gênero elegíaco. $\mathrm{O}$ presente artigo consistirá numa breve apresentação do mencionado poema, enfocando particularmente o motivo do cenário aprazível, em sua relação com a elegia e com outros gêneros poéticos.

Palavras-chave: Propércio I.20; elegia; locus amoenus; mito de Hilas; metapoesia. 
Abstract: Propertius I.20 is often pointed out as a complex, or rather obscure composition by the critics. In this 52-verse elegy, Propertius, dealing with a pederastic theme, recalls the episode of the rape of Hylas, and draws a parallel between the famous myth and the actual situation experienced by Gallus on the plane of love. By doing so, Propertius employs several elements typical of a locus amoenus, in order to describe the setting where the events narrated take place. In fact, a close examination shows how this topos, too, receives a metapoetical treatment, insofar as certain words and images associated to it seem to refer directly to the elegiac genre. This paper, thus, will consist of a brief presentation of the mentioned poem, particularly focusing on the motive of the pleasant landscape, in its relationship with the elegy and other genres as well.

Keywords: Propertius I.20; elegy; locus amoenus; Hylas myth; metapoetry.

Recebido em 18 de fevereiro de 2015.

Aprovado em 17 de junho de 2015.

\section{Introdução: Propércio I.20}

Possivelmente uma das primeiras composições de Propércio, o poema I.20 é o mais extenso do poeta, com 52 versos - e também o mais extravagante e obscuro, conforme apontam certos comentadores (HODGE; BUTTIMORE, 2002, p. 202). Embora questionável, essa hipótese é amplamente disseminada entre os críticos, que levam em conta o elevado número de palavras de quatro ou mais sílabas no final do verso, e também o "estilo" mais "alexandrizante" observado no poema. ${ }^{1}$ Trata-se de uma elegia endereçada a Galo - se este corresponde

\footnotetext{
${ }^{1}$ FEDELI, 1980, p. 454: "La fama del mito di Ila presso gli Alessandrini, la dipidenza di Properzio da una o più fonti greche e il fatto che questa sia probabilmente una delle prime elegie properziane - come ritengono alcuni critici sulla base dell'elevato numero di parole di 4 o più sillabe alla fine del verso - spiegano l'uso, più accentuato qui che nelle altre elegie, di uno stile alessandrineggiante; esso conferisce al contesto
} 
ao famoso poeta romano, não se sabe dizer -, a quem o eu poético dirige uma contundente advertência, ou antes um conselho experiente, para que o amigo não deixe seu amante cair nas garras das mulheres: Hoc pro continuo te, Galle, monemus amore,/(id tibi ne uacuo defluat ex animo)/ saepe imprudenti fortuna occurit amanti. ${ }^{2}$

Se por um lado o nome de Galo está presente em outras elegias propercianas - antes de I.20, já encontramos a referência a ele em I.5, 10 e 13 -, o motivo do amor pederástico, por outro lado, é algo completamente novo e aparece isolado não só no primeiro livro, mas em toda a obra de Propércio (FEDELI, 1980, p. 455). A fim de ilustrar os perigos a que o seu destinatário está sujeito neste campo minado que é o amor, o eu poético recorre ao conhecido episódio de Hilas como estratégia para persuadir o amigo a se manter vigilante com seu puer delicatus. Este, conforme nos é revelado, além de equiparar-se ao jovem grego em beleza, teria ainda o mesmo nome que ele - est tibi non infra speciem, non nomine dispar,/ Theiodamanto proximus ardor Hylae. ${ }^{3}$ Assim, suspende-se aquele primeiro registro coloquial para se adentrar no maravilhoso plano mítico.

Seguindo de perto o costume dos alexandrinos, Propércio faz um relato minucioso do mito, o que não é comum se considerarmos a totalidade de sua produção - mais usualmente, quando se recolhe material da mitologia grega, é com a finalidade de tecer comentários ou alusões

un carattere aulico, anche se non mancano forzature e periodi faticosi o contorti: li ha messi in luce il La Penna Prop. 133. Ciò rende verisimile l'ipotesi di Curran 'Gr. Rom. Byz. Stud.' 5 (1964) 281, che ritiene 1,20 un esperimento, nell'uso di uno stile esemplato sulla lingua greca e di miti greci (...)".

${ }^{2}$ PROPÉRCIO, I.20, v. 1-3: "Por seu contínuo Amor eu te aconselho, Galo,/ e que isso não te saia da cabeça!/ Fortuna se opõe sempre ao amante imprudente". Faremos uso, ao longo deste artigo, da edição de W. A. Camps (1961) e da tradução recente de Guilherme Gontijo Flores (2014).

${ }^{3}$ PROPÉRCIO, I.20, v.5-6: "Não tem menor beleza, nem renega o nome: teu fogo é como o Teodamânteo Hilas". Cf. CURRAN, 1964, p. 287 (grifos dele): "The boy Gallus loved must in fact have been named Hylas. We are pointedly told that Gallus' beloved is non nomine dispar to the legendary Hylas [5]. Whatever the common figurative meanings of nomen, the plain meaning of non nomine dispar is 'not unlike in name,' i.e., 'like in name'. The natural interpretation of the last line in the poem is 'you who have been seen entrusting Hylas to the Nymphs'. The probability that the boy's name actually was Hylas gives much more point to the mocking insistence with which Propertius plays with the sounds of the name and its etymology". 
breves, pontuais; em I.20 (e também em III.15), ao contrário, Propércio explora em detalhes as implicações sugestivas e imaginativas de um único mito, que ocupa papel central no poema (CURRAN, 1964, p. 282). Apesar disso, é importante ressaltar que, mesmo nesse caso, a narrativa mitológica em Propércio assume uma função diversa daquela que se vê na elegia e no epílio alexandrinos: afinal, o que está em jogo em I.20, bem como em III.15, não é o "mito pelo mito", mas sim o exemplo que se pode extrair dele. ${ }^{4}$ Analisando a questão sob esse ângulo, portanto, percebe-se que o relato do episódio de Hilas presente em I.20, embora consideravelmente extenso, ao mesmo tempo em que não constituiria uma grande novidade em relação às demais alusões mitológicas que o poeta faz, mais brevemente, em outras elegias, também não se caracterizaria simplesmente como uma forma de epílio ou de narrativa elegíaca à maneira dos alexandrinos. ${ }^{5}$ Em sua qualidade de exemplum, que remete à situação "atual" na qual se encontra Galo (CAMPS, 1961, p. 93; FEDELI, 1980, p. 455), referida no início e no final do poema, diríamos, antes, que a narrativa de Hilas não passaria de uma longa digressão; digressão essa que, pelo tratamento a ela dado, ganharia destaque e, por

\footnotetext{
${ }^{4}$ CAMPS, 1961, p. 9: "A characteristically Propertian feature of these poems is the abundance of mythological allusion. This habit was favoured by the rhetoricians' method, taught at school, of enumerating examples to support an argument. It was favoured also by the example of the Hellenistic poets, who were fond of assembling and reciting legends that had some common element (loves of gods, loves of poets, unhappy loves, etc.); indeed, a Greek named Parthenius had compiled for Gallus a book (in prose) of tales of unhappy love expressly to be used as a source of allusions in his own poetry".

${ }^{5}$ FEDELI, 1980, p. 487: "Nell'incertezza della fonte usata da Properzio è ozioso continuare a chiedersi se 1,20 sia un epillio (Rothstein 186 e, forse, Wilamowitz Hell. Dicht. I 233) o un'elegia a imitazione dell'elegia narrativa alessandrina (Abel Anred. 133-134, La Penna Prop. 136-138). Certo, un epillio alessandrino non sarà stato in toto identico ad un'elegia del tipo di 1,20: perlomeno la parte 'atualle', qui presente all'inizio e alla fine, diferenzia 1,20 dall'epillio. È ovvio, inoltre, che Properzio tratti con sensibilità diversa materia ellenistica, magari tratta da un epillio. Su questi motivi rinvio a quanto ho scritto in 'Mus. Helu.' 31 (1974) 34-35 a proposito della ripresa dell'epillio alessandrino da parte di Properzio e del suo adattamento nello schema elegiaco. Mi sembra, comumque, che tracce dell'influsso dell'epillio siano ravvisabili nell'indeterminatezza di alcuni particolari narrativi e nella presenza di un'importante digressione (v. 25-30), che s'inserisce nel corso della narrazione principale".
} 
um momento, acabaria até ofuscando aquele que seria o foco do poema: o perigo iminente, "real", que se acerca de Galo.

Com relação às possíveis fontes usadas, o mito de Hilas, em Propércio, ecoa Teócrito (Idílio 13) e Apolônio de Rodes (I.1182-1272), ${ }^{6}$ com predominância do primeiro, haja vista o rapto daquele personagem por várias ninfas (PROPÉRCIO, I.20, v. 25-47; TEOCRITO, XIII, v. 48-49), e não por uma só, como se verifica em Apolônio. A versão mais conhecida desse mito - que era, com efeito, bastante recorrente na arte e na decoração romana, e inclusive aparece aludido nas Geórgicas de Virgílio (III.6: cui non dictus Hylas puer?) - nos é descrita por Grimal, em seu Dicionário de mitologia grega e romana:

Quando Héracles combatia os Dríopes, matara-lhes o rei Teódamas e raptara o filho deste, Hilas, um jovem de grande beleza, por quem ele se apaixonara. Hilas acompanhou-o na expedição dos Argonautas. Mas, durante uma escala na Mísia, enquanto Héracles fora cortar uma árvore para fazer um remo (pois aquele de que até então se servira havia-se quebrado), Hilas fora incumbido de ir buscar água a uma fonte, na floresta, ou então ao rio (ou lago) Ascânio. As Ninfas, achando-o tão belo, atraíram-no a si para lhe concederem a imortalidade. Polifemo, que desembarcara com Hilas e Héracles, foi o primeiro a dar pelo desaparecimento do jovem. Chamou-o durante muito tempo, mas em vão. Héracles juntou os seus gritos aos dele. Entretanto, os Argonautas tinham levantado âncora, sem esperar pelos seus companheiros (possivelmente a conselho dos Boréadas). Polifemo fundou neste lugar a cidade de Cio, que mais tarde se chamou Prusa. Héracles, pensando que os Mísios teriam raptado Hilas, impôs-lhes reféns e ordenou-lhes que procurassem o jovem, o que os Mísios ainda faziam solenemente no decurso duma festa anual: os sacerdotes marchavam em procissão até a montanha mais próxima e gritavam três vezes o nome de Hilas. (GRIMAL, 2005, p. 228)

${ }^{6}$ CAMPS, 1961, p. 93; RICHARDSON Jr., 1977, p. 201. 
É quase certo, porém, que Propércio, além de ter presumivelmente bebido da fonte de Teócrito e de Apolônio de Rodes, tenha reinventado certas partes do mito - por exemplo, a cena da perseguição do jovem Hilas pelos Bóreadas (v. 25-30), da qual não se tem nenhum outro registro senão a própria elegia I.20 $-^{7}$ ou que, ainda, tenha-se pautado numa terceira versão, menos difundida (FEDELI, 1980; RICHARDSON Jr., 1977, p. 201).

Seja como for, a narrativa do rapto de Hilas cumpre um papel bastante específico na elegia de Propércio, que é, como já dissemos, o de fornecer um exemplo, uma advertência a Galo - talvez até, segundo a hipótese de Curran (1964, p. 282 e 287), com certo tom de sarcasmo e ridicularização. Assim, poderíamos dizer que o mito em I.20 estaria subordinado à temática do amor - o que não é de se surpreender, considerando as convenções e a matéria próprias do gênero elegíaco. $\mathrm{E}$ precisamente nesse contexto erótico-amoroso, em que tudo (ou quase tudo) é permeado pelo desejo cúpido, libidinoso, é notável que o cenário também acabe sendo contaminado pelas cores intensas da luxúria. De fato, em Propércio I.20 as referências aos atributos da natureza são constantes, as imagens vivazes e aguçadoras dos sentidos. Mais do que uma mera paisagem de fundo, a natureza em Propércio - e não só nele - desempenha um papel influente no desenrolar dos eventos, e tem participação ativa sobre o ânimo dos humanos, e mesmo das divindades.

\section{O locus amoenus em Propércio I.20}

Em diversos episódios da mitologia grega, a floresta, a natureza de um modo geral, aparece como palco de realização do desejo eróticoamoroso. Longe da agitação da cidade e dos olhares inquisidores dos vizinhos, num bosque apartado, os amantes se veem livres para dar vazão às suas fantasias e instintos latentes. Ao mesmo tempo, é nesse lugar recluso que os homens lascivos perdem o controle de si e violentam moças virgens; ou que deusas e deuses, sem nenhum pudor, perseguem jovens mortais. Na floresta, Apolo, ferido pela flecha de Cupido, correu incansavelmente atrás de Dafne, até que esta, exausta, se transformasse num loureiro, graças à ajuda do pai (OVÍDIO, Met., I, 452 et seq.). Na floresta, Aristeu tentou de todas as formas apoderar-se de Eurídice,

\footnotetext{
${ }^{7}$ FEDELI, 1980, p. 457.
} 
fazendo com que a infeliz amada de Orfeu, durante a fuga, pisasse numa serpente venenosa (VIRGÍLIO, Georg., IV, 317 et seq.). Num campo afastado, Hades, impaciente, raptou Perséfone, enquanto esta colhia distraidamente flores (OVÍDIO, Fast., IV, 417 et. seq.; Met., V, 393 et seq.). Até mesmo o bardo William Shakespeare (1564-1616), valendo-se desta e de outras tópicas ao compor a comédia Sonho de uma noite verão (c. 1590-1596), conduzirá quatro adolescentes apaixonados e impetuosos a uma floresta, onde fará com que eles vivam, no espaço de uma noite e sob os efeitos de uma poção mágica, os mais variados enganos no plano amoroso. Ao menos no que diz respeito às questões de amor, portanto, a floresta pode ser vista tradicionalmente como um cenário de aventura (perigo) e sedução (perdição).

Particularmente na elegia I.20 de Propércio, o cenário no qual Hilas aparece inserido constitui-se como floresta sedutora e perigosa, por um lado, e como lugar ameno e tranquilo, por outro. A literatura clássicae com esta nomenclatura um tanto genérica queremos apenas nos referir, de modo amplo, a um tipo de produção poético-retórica que perdurou no ocidente até pelo menos o século XVIII, antes do Romantismo - está repleta de exemplos dessa natureza aprazível. Já em Homero (c. IXVIII a.C.), e mais especificamente na Odisseia, nos deparamos com um número considerável de amostras da paisagem ideal, como no caso da descrição dos abençoados Campos Elísios (Od., IV, v. 565 et seq.), da maravilhosa gruta de Calipso (V, v. 63 et seq.), ou do opulento jardim do rei feácio Alcínoo (VII, v. 112 et seq.). Igualmente notáveis são as referências à gruta consagrada às ninfas em Itaca (Od., XIII, v. 102 et seq.), ao Olimpo (VI, 42 et seq.), e mesmo à ilha dos Ciclopes selvagens (IX, v. 132 et seq.). Em Homero, com efeito, a natureza desempenha um papel preponderante, participando de tudo aquilo que é ou tem relação com o divino. Da paisagem homérica poetas de todos os tempos puderam extrair alguns dos motivos que formariam as bases de uma longa série de esquemas recorrentes, como é o caso da tópica do locus amoenus (CURTIUS, 1990, p. 186).

Ainda que então despojado de seu estatuto de tópica, passível de catalogação em manuais de poética e retórica, por exemplo - algo que viria a se constar somente na chamada Baixa Idade Média,$-{ }^{8}$ já no

\footnotetext{
${ }^{8}$ CURTIUS, 1990, p. 197: "In the Middle Ages the locus amoenus is listed as a poetical requisite by lexicographers and writers on style. We encounter a great number of such
} 
período do Império Romano a descrição do locus amoenus aparece como um modelo bastante difundido na poesia. ${ }^{9} \mathrm{Na}$ Arte Poética (18 a.C.), Horácio sugere reconhecer, com ironia,o amplo uso desse costume, ao qual certos poetas poderiam recorrer inabilmente, com a esperança vã de obter algum efeito na poesia: Inceptis grauibus plerumque et magna professis/purpureus, late qui splendeat, unus et alter/ adsuitur pannus, cum lucus et ara Dianael et properantis aquae per amoenos ambitus agros/ aut flumen Rhenum aut pluuius describitur arcus:/ sed nunc non erat his locus. ${ }^{10}$

Tendo isso em vista, é possível dizer que, embora não houvesse teorização a respeito, na época de Propércio (43 a.C.-17 d.C.) o topos do lugar ameno já se caracterizava como uma forma que circulava nos mais variados contextos poéticos, e encontrava respaldo na produção de autoridades como Homero - "considerado por retores antigos como a grande fonte e modelo de gêneros" (ACHCAR, 1994, p. 27) -, Hesíodo (HESÍODO, Os trabalhos e os dias v. 109 et seq. e 167 et seq.), Teócrito e Virgílio. Estes dois últimos, na verdade, seriam os poetas que, através da poesia de cunho pastoril - Teócrito (310-250 a.C.) com os Idílios, Virgílio (70-19 a.C.) com as Bucólicas -, teriam dado a maior contribuição à disseminação e posterior fixação da tópica (CURTIUS, 1990, p. 190). De fato, compor sob a moldura pastoril apresentaria ao poeta uma ocasião favorável para que ele pintasse um locus amoenus com todos os seus atributos característicos - uma fonte de água fresca, árvores frutíferas e umbrosas, clima aprazível. Pensando nisso, poderíamos até inferir que Propércio, ao instaurar na sua elegia I.20 uma natureza com elementos que remetem o leitor àquele esquema descritivo, estaria jogando com uma convenção mais típica do gênero bucólico, o que de certo modo atestaria também a afinidade entre este tipo de poesia e a poesia erótica. ${ }^{11}$

pleasances in the Latin poetry which flourished from 1070 onwards. Model examples are also to be found in the arts of poetry which began to appear in increasing numbers from 1170".

${ }^{9}$ CURTIUS, 1990, p. 195.

${ }^{10}$ HORÁCIO, Ars Poet. v. 14-19: "Geralmente a princípios solenes e onde se prometem grandes coisas, para obter mais efeito, qualquer remendo purpúreo se lhes cose, ao descrever o bosque e o altar de Diana, as curvas de rápidos ribeiros por amenos campos, ou o Reno ou o chuvoso arco-íris; ali, porém, não cabiam tais descrições". (trad. R. M. Rosado Fernandes)

${ }^{11}$ CURTIUS, 1990, p. 199-200: As we have seen, the locus amoenus also formed part of the scenery of pastoral poetry and thus of erotic poetry. Cf. também VIRGÍLIO, Buc. X. 
Logo no início da elegia I.20, antes mesmo de adentrar na narrativa do rapto de Hilas, encontramos alusões à natureza:

Huic tu, siue leges umbrosae flumina siluae, siue Aniena tuos tinxerit unda pedes, siue Gigantea spatiabere litoris ora, siue ubicumque uago fluminis hospitio 10

Nympharum semper cupidas defende rapinas (non minor Ausoniis est amor Adryasin). ${ }^{12}$

Sabe-se que a sombra é um atributo recorrente nas descrições do lugar ameno. Na poesia pastoril, é sob a copa de uma árvore que o pastor, frequentemente, encontra o repouso necessário para os trabalhos, e entrega-se aos deleites da música, da conversação, do ócio. Nas Bucólicas, temos exemplos consideráveis do emprego dessa imagem, inclusive na abertura da obra:

Mel. Tityre, tu patulae recubans sub tegmine fagi, siluestrem tenui musam meditaris auena: nos patriae fines et dulcia linquimus arua; nos patria fugimus: tu, Tityre, lentus in umbra formosam resonare doces Amaryllida siluas. ${ }^{13}$

Sobre o uso de umbrosus no verso 7 (umbrosae... siluae) da passagem properciana acima transcrita, mais especificamente, Fedeli (1980, p. 462) comenta que esse "é um dos tantos adjetivos em -osus, prediletos dos elegíacos" (trad. nossa); sendo ele, em particular, dotado

\footnotetext{
${ }_{12}$ PROPÉRCIO, I.20, v.7-12: "Se tu segues um rio pelas selvas da Úmbria,/ ou se tinge teus pés a onda Aniena,/ se tu passeias pela costa dos Gigantes,/ ou se um rio vagante der refúgio,/ defende-o sempre contra Ninfas de rapina/ (não é menor o Amor das Hamadríades)". Percebe-se, aqui, que na edição utilizada por Guilherme Flores (2014), no lugar da expressão umbrosae ... siluae, temos Vmbrae ... siluae ("selvas da Úmbria"). Conforme dissemos na nota 3, contudo, seguimos a edição de Camps (1961), que adere à primeira lição.

${ }^{13}$ VIRGÍlLIO, Buc. I, v. 1-5: "Mel. Tu, sob a larga faia reclinado,/ Silvestre musa em tênue cana entoas:/ Nós, Títiro, da pátria os fins deixamos/ $\mathrm{E}$ a doce lavra, a pátria nós fugimos;/ As selvas tu, pausado à sombra, ensinas/ Amarílis formosa a ressoarem". (trad. Odorico Mendes)
} 
de um valor predominantemente poético. Em seguida, no verso 9, vemos uma referência às praias dos gigantes (Gigantea ... litoris ora), que, ainda segundo Fedeli (ibid.), designaria o litoral de Cuma - e não os Campos Flégreos, onde teria ocorrido a batalha mítica dos deuses contra os gigantes; trata-se, antes, do "tradicional local de delícias e de perdições para as castae puellae e para os pueri delicati" (ibid., p. 455, trad. nossa). Assim, observa-se que Propércio estabelece de antemão uma relação de igualdade entre esses quatro lugares - a floresta umbrosa, as margens do rio Ânio, o litoral de Cuma, o refúgio de um vagante rio -, no sentido de que todos eles, inclusive a floresta umbrosa, representam um perigo ao amante.

A partir do verso 15 , quando o eu poético faz menção ao infeliz erro de Hércules para que sirva de lição ao seu destinatário - quae miser ignotis error perpessus in oris/ Herculis indomito fleuerat Ascanio,$-{ }^{14}$ Propércio suspende o tempo primário do poema, abre parênteses e começa a relatar o fatídico episódio que ocasionou o rapto de Hilas. Assim ele começa a narrar a jornada dos Argonautas rumo à Cólquida, e a parada que os heróis fizeram na Mísia:

\section{Namque ferunt olim Pagasae naualibus Argon egressam longe Phasidos isse uiam, et iam praeteritis labentem Athamantidos undis Mysorum scopulis applicuisse ratem.}

Hic manus heroum, placidis ut constitit oris, mollia composita litora fronde tegit. ${ }^{15}$

Contextualmente, temos exemplos que nos remetem a esta mesma situação na Odisseia, quando, por exemplo, Odisseu chega à Feácia, depois de uma longa tribulação infligida a ele pelo deus Posídon:

\footnotetext{
${ }^{14}$ PROPÉRCIO, I.20, v. 15-16: "Pois Hércules em meio a margens nunca vistas/ pôsse a chorar perante o Ascânio indômito". Chamamos a atenção do leitor, neste trecho, para o uso de miser - adjetivo caro aos poetas elegíacos (PICHON,1991, p. 202-203) - modificando o substantivo error ("o infeliz erro de Hécules").

${ }^{15}$ PROPÉRCIO, I.20, v. 17-22: "Dizem que outrora, quando Argos saiu de Págasa,/ fez um longo percurso rumo ao Fásis,/ após ultrapassar as ondas da Atamântide/ nos recifes dos Mísios aportou./ Quando os heróis pisaram nessas margens plácidas,/ com folhas transformaram praia em leito".
} 
(...) debaixo duma árvore pôs-se,
dupla, porém, tendo só uma raiz: zambujeiro e oliveira.
Não conseguia vará-las o vento que traz umidade,
nem com seus raios brilhantes o Sol o local clareava,
nem mesmo a chuva até lá penetrava, por tal modo
[unidas
e entrelaçadas cresceram as árvores onde o guerreiro
fora acolher-se. Arranjou, muito às pressas, com as
[mãos uma cama
larga, pois tanta abundância de folhas havia no solo,
que de coberta chegara, talvez, para dois ou três
[homens,
quando no inverno, por mais rigoroso que entrado ele
fosse.
Vendo-a formada, o paciente e preclaro Odisseu
[alegrou-se
e, bem no meio deitando-se, cobre-se todo com folhas. ${ }^{16}$

Em ambos os relatos conta-se que os heróis, ao aportarem numa praia, se colocam para descansar sobre um leito de folhas improvisado por eles. Percebe-se, pois, a existência de uma convenção de ordem mítico-poética - para não falar de um suposto costume cultural que nos remeteria à Grécia (pré-)homérica -: é comum o herói, após uma viagem, buscar repouso num cenário tranquilo, onde possa recobrar as forças e se alimentar. O mesmo se verifica nas Argonáuticas de Apolônio de Rodes; ${ }^{17}$ e também na Eneida Virgílio recorre a essa espécie de topos ao narrar, no Canto I, o momento em que os troianos, depois de enfrentarem uma dura tempestade provocada por Éolo a pedido de Juno, decidem parar numa praia da Líbia. ${ }^{18}$

\footnotetext{
${ }^{16}$ HOMERO, Odisseia V, v. 476-487. (trad. Carlos Alberto Nunes)

${ }^{17}$ APOLÔNIO DE RODES, Arg., I, v. 1179-1186: “Acogiéronlos al llegar con honores de huésped y en son de amistad/ los Misios, que aquellas tierras habitan, y les ponían en las manos/ víveres, corderos y vino sin cuento, pues tenían buena falta de ello./ Inmediatamente después unos héroes traían maderos resecos, otros/ habían cogido en los prados miles de hojas que sirven de lecho/ con el fin de extenderlas, y otros encendían el fuego haciendo girar unos troncos; /otros, en fin, en crateras mezclaban el vino y disponían también la comida,/ tras haber hecho antes un sacrificio en la noche a Apolo, dios del Desembarque". (trad. Manuel Pérez Lópes, grifo nosso)

18 "Cansados os Enéadas forcejam/ por arribar à terra mais vizinha,/ e de Líbia às
} 
Em Propércio I.20, no trecho acima, encontramos a expressão placidis ... oris (v.21) - que pode ser traduzida como "paragens tranquilas", "margens plácidas" - na descrição do cenário. É sintomático, porém, que, conforme iremos descobrir, o lugar é tranquilo apenas na aparência (RICHARDSON Jr., 1977, p. 204). Ou melhor, o lugar, em princípio, seria tranquilo de fato; mas o amor, o desejo erótico irrefreável, é capaz de desestabilizar essa ordem.

Ainda considerando o mesmo trecho, verifica-se o emprego do adjetivo mollis (mollia, v. 22) como proléptico para se referir às areias tornadas macias com a cobertura de folhas. Sabe-se que o uso de mollis - adjetivo que, além de indicar a qualidade da maciez, pode também, por extensão, conotar algo delicado, tenro; ou mesmo voluptuoso, luxuriante ,$-{ }^{19}$ assim como do verbo a ele correspondente - mollio -, é frequente na poesia elegíaca. A título de ilustração, nos Amores de Ovídio, temos a emblemática passagem em que o eu poético declara, no poema de abertura do livro II: blanditias elegosque leuis, mea tela, resumpsi;/ mollierunt duras lenia uerba fores. ${ }^{20}$ Desse modo, cogitamos a possibilidade de esse adjetivo estar sendo empregado por Propércio não só com aquela acepção mais imediata, que diz respeito à maciez literal da areia, mas também, talvez, com um sentido mais sutil, quase metafórico ou metapoético: com a chegada dos Argonautas à praia da Mísia - e mais importante, com a chegada de Hilas àquele local - todo o cenário, a começar pelo solo, tornou-se mais delicado, elegíaco.

Na sequência, Propércio narra o momento em que Hilas se afasta do grupo para procurar água numa fonte - at comes inuicti iunenis processerat ultra/raram sepositi quaerere fontis aquam. ${ }^{21}$ Aqui, a locução raram aquam apresentaria um sentido dúbio, ambíguo, e poderia ser interpretada de maneiras distintas: ou a água seria rara por ser de difícil

regiões a proa inclinam./ N'uma longa enseada um sítio existe:/ um ilhote o resguarda e faz bom porto (...)./ Por cima logo/ de trêmulos arbustos grata cena/ e um negro bosque de medonha sombra/ iminentes estão: na face oposta/ debaixo de uns penhascos pendurados/ um antro existe; dentro doces fontes/ e assentos naturais na rocha viva,/ habitação das ninfas". (trad. José Victorino Barreto Feio, 2004, p. 11-12, grifo nosso) ${ }^{19}$ OLD: "mollis", 1968, p. 1127-1128.

${ }^{20}$ OVÍDIO, Am., II, v. 21-22: “As carícias e as leves elegias, que são minhas armas, eu retomei;/ palavras brandas puderam amolecer portas duras". (trad. nossa)

${ }^{21}$ PROPÉRCIO, I.20, v. 23-24: "Porém o amigo do invencível jovem longe/ foi buscar água em fontes afastadas". 
acesso; ou porque seria escassa no local; ou porque, ainda, seria uma água de qualidade excepcional, incomum. ${ }^{22}$ Camps (1961, p. 95) acha a segunda interpretação mais improvável; e a respeito da última suposição, também considera o emprego do adjetivo raram com o sentido de non communem ou tenuem ("clara", "límpida", "transparente"), conforme este aparece empregado nos Fastos (II, 250) de Ovídio: et tenuem uiuis fontibus adfer aquam. ${ }^{23}$

Seguindo essa mesma linha de raciocínio e levando em consideração a nossa hipótese cogitada acima, poderíamos ir além e dizer que o adjetivo rarus, neste contexto específico, carregaria também um significado metapoético - com efeito, o jovem Hilas distancia-se dos seus companheiros "épicos" para ir buscar água numa fonte cristalina e "elegíaca", isto é, numa fonte sedutora, afrodisíaca. Em tempo, vale lembrar que, assim como o adjetivo mollis, rarus também integra o léxico seleto da poesia erótica. Mais uma vez recorrendo a Ovídio - poeta que, segundo a tradição, teria revelado os segredos do gênero elegíaco -, encontramos, em Amores I.5, uma dentre muitas ocorrências do adjetivo rarus aplicado à famosa descrição das vestes de Corina: Deripui tunicam; Nec multum rara nocebat. ${ }^{24}$

Exemplo ainda mais concreto dessa erotização do cenário se poderá constatar no próximo quadro, que diz respeito à aparição dos gêmeos Zetes e Cálais. Conforme se sabe, estes seriam, na mitologia grega, os filhos alados de Bóreas, e personificariam os ventos - sendo Cálais "o que sopra docemente", e Zetes "o que sopra com força" (GRIMAL, 2005, p. 61). No poema em apreço, os jovens, excitados, empreendem um ataque aéreo ao indefeso Hilas, roubando-lhe beijos e

\footnotetext{
${ }^{22}$ FEDELI, 1980, p. 472 (grifos dele): “[L]'acqua, cioè, è definita rara perché è di difficile reperimento (ma questo contrasterebbe con quanto dice Teocrito), o perché il luogo scarseggiava di sorgenti (ma non si capisce quale utilità abbia una tale specifiazione da parte di Properzio)? Oppure rara è un aggetivo destinato a nobilitare il sostantivo cui si riferisce (come in 1, 8, 42 Cynthia rara mea est) e a designare l'eccezionale, unica limpidezza dell'acqua, sottolineando al tempo stesso il carattere sacro del luogo abitato dalle ninfe (e in tal caso potrebbe esservi un richiamo al ícòv @óov di Apollonio Rodio)? Per quest'ultimo significato Camps mi comunica il rinvio a Martial 2, 86, 12 raris ('pregiati') auibus e a Lucan 4,123 iam rarior ('meno torbido') aer".

23 "E traga, das fontes vívidas, a límpida água". (trad. nossa)

${ }^{24}$ OVÍDIO, Am., I, 5, v. 13: "Arranquei-lhe a túnica; transparente, não estorvava tanto". (trad. Lucy Ana de Bem)
} 
suspendendo-o no ar; de onde se depreende que nem mesmo os ventos estão imunes aos encantos do amante de Hércules:

\author{
Hunc duo sectati fratres, Aquilonia proles, \\ hunc super et Zetes, hunc super et Calais, \\ oscula suspensis instabant carpere palmis, \\ oscula et alterna ferre supina fuga. \\ Ille sub extrema pendens secluditur ala \\ et uolucres ramo summouet insidias. ${ }^{25}$
}

Numa tentativa desesperada de se livrar deles, Hilas recorre a um ramo de árvore com a intenção de repelir as ameaças dos Boréadas. E aqui, novamente, o leitor é posto diante de um vocábulo reincidente na poesia erótica - insidiae -, o qual aparece também em Catulo, Tibulo e Ovídio. ${ }^{26}$ Mal consegue se safar da mira dos irmãos alados, porém, Hilas vai buscar abrigo junto a uma fonte, sob o vértice do monte Arganto (v. 33: Arganthi Pege sub uertice montis). Nesse ponto, encontramos uma descrição vivaz do locus amoenus. Trata-se da residência aquática das Ninfas, local onde se encontram árvores solitárias que, sem a necessidade de cultivo algum, produzem frutos orvalhados (v. 35-36: supra nullae pendebant debita curae/ roscida desertis poma sub arboribus). ${ }^{27}$

\footnotetext{
${ }^{25}$ PROPÉRCIO, I.20, v. 25-30: "Dois irmãos o seguiram - proles Aquilônicas -/ sobre ele vinha Zetes, vinha Cálais,/ com pés suspensos cobiçavam colher beijos/ e alçavam alternando ao céu seus beijos./ No entanto ele se esconde embaixo de uma asa/ e com um galho afasta o assédio aéreo".

${ }^{26}$ PICHON, 1991, p. 173: Insidiae aliquotiens proprio sensu accipiuntur, et sunt doli ad aliquem furtim deprehendendum conpositi: Ov., Ars Am., II, 593-594: uetat deprensa Dione insidias illas, quas tulit ipsa, dare./Alias insidiae sunt conatus riualium puerum aut puellam rapere studentium: Cat., XV, 16: ut nostrum insidiis caput lacessas; cf. Cat., XXI, 7; Prop., I, XX, 30./ Sed plerumque insidiae sunt fraudes ad amorem conciliandum paratae, seu a uiris in puellas: Ov., Ars Am., I, 134: theatra nunc quoque formosis insidiosa manent; - cf. Ov., Her., XIX, 66; XX, 110;/ seu a feminis in amantes: Prop., III, XXV, 6: semper ab insidiis, Cynthia, flere soles; - cf. Ov., Am., II, IV, 12./ Eodem sensu dicunt poetae insidias struere Amorem: Tib., I, VI, 4: insidias homini conposuisse deum; - cf. Ov., Rem., 148./ Insidiae sunt etiam doliquibus amantes, ut fallant, utuntur: Prop., II, XXXII, 19: insidias in me conponis inanes; - cf. Ov., Her., X, 6; Ars Am., III, 539.

${ }^{27}$ Em minha pesquisa de Iniciação Científica (FONSECA Jr., 2012), a partir da
} 
Precisamente nessa paisagem aprazível, dar-se-á o arrebatamento final de Hilas pelas Dríades, ninfas das florestas que são representadas por Propércio como amantes elegíacas, ardendo de desejo amoroso (v. 45: accensae Dryades ... puellae).

Nesse contexto, concluímos que certas escolhas lexicais em Propércio I.20 são modelares na descrição do cenário, sendo parte delas responsável por conferir um caráter tipicamente elegíaco à natureza retratada. Umbrosus, mollis, rarus são exemplos concretos de adjetivos que, de um modo geral, são recorrentes no gênero, e que integram a descrição da paisagem aprazível no poema analisado. Acrescente-se a estes, ainda, o emprego de formosis no verso 41, modificando o substantivo undis; e de blandis, na sequência, fazendo par com imaginibus - et modo formosis incumbens nescius undis/ errorem blandis tardat imaginibus. ${ }^{28}$ É interessante notar que o mesmo adjetivo formosus, usado para qualificar as ondas, reaparecerá no último verso do poema, só que para caracterizar o Hilas de Galo - His, o Galle, tuos monitus seruabis amores, / formosum Nymphis credere uisus Hylan. ${ }^{29}$ Tal observação tornaria ainda mais relevante a hipótese suscitada por Curran (1964, p. 288), de que a conexão etimológica verificada entre os nomes Hylas e v̌ $\lambda \eta$ ("floresta", em grego) leva a crer que haja uma identificação entre aquele personagem e o cenário retratado: "Por causa de seu próprio nome, Hilas é a floresta. Seu devido lugar, portanto, é na natureza, não numa expedição heroica, e é apenas certo que ele se torne unido à primavera silvestre" ( $i b i d$., trad. nossa). Ademais, essa interpretação seria reforçada pela presença das Dríades na cena do rapto, em substituição às Náiades, que são as ninfas dos rios e lagos. ${ }^{30}$ Pensando nisso, e com base em

observação de algumas amostras poéticas, pude notar que, frequentemente, a não necessidade do cultivo indicaria um lugar ameno do tipo divino, em contraposição ao lugar ameno campestre ou civilizado. Nestes, a fertilidade da terra e a abundância de frutos dependeria, em grande medida, do trabalho humano.

${ }^{28}$ PROPÉRCIO, I.20, v. 41-42: "E tolo sobre as belas ondas vai pendendo/ e alonga seu passeio em doce imagem".

${ }^{29}$ PROPÉRCIO, I.20, v. 51-52: "Com tais conselhos, Galo, guarda os teus Amores,/ pois quase deste às Ninfas o teu Hilas".

${ }^{30}$ CURRAN, 1964, p. 287-288 (grifos dele): "Although it is true that ancient poets are not always precise in assigning functions to the various categories of nymphs, Propertius seems to go out of his way to insist by means of three different Greek terms that his nymphs are wood nymphs. He calls them Dryads, Adryads, and Hamadryads. For one 
nossas conjecturas desenvolvidas ao longo deste artigo, seria tentador fazer uma emenda na afirmação de Curran e dizer que, de fato, o lugar do belo Hilas não é numa expedição épica, mas sim no cenário elegíaco, desfrutando - ou melhor, sendo objeto - do amor.

\section{Considerações finais}

Neste artigo, vimos brevemente que a descrição do cenário natural apresentada em Propércio I.20 englobaria todos os atributos essenciais de um lugar ameno - motivo esse que está presente em outros gêneros poéticos, desde o épico até o pastoril. Nela encontramos a fonte cristalina, o recanto de sombras, as árvores e flores; enfim, todos os elementos que conferem a beleza e a tranquilidade características da tópica do locus amoenus. Tais qualidades seriam ressaltadas, ainda, pelo emprego de certos adjetivos que remeteriam o leitor ao gênero elegíaco - como no caso de mollis, rarus, formosus... Com efeito, da leitura do poema é possível constatar que aquela tranquilidade do local narrado seria apenas aparente; ora, é precisamente nessas "margens plácidas" que se dará o violento rapto de Hilas, primeiro pelos Boréadas, depois pelas Dríades o que acaba confirmando o argumento inicial proferido pelo enunciador do poema, de que aonde quer que ande o puer delicatus de Galo, este deve manter-se sempre atento aos perigos a que seu amante está exposto. Assim, chegamos à conclusão de que o emprego daqueles adjetivos, somado à ocorrência de outros vocábulos e imagens expressivas, gera um efeito no poema que beira ao metapoético: considerando que tais modificadores frequentemente recebem um tratamento distintivo na elegia, ao serem aplicados na descrição do cenário, eles estariam apontando para um contexto elegíaco, senão para o próprio gênero. Levando a cabo esta hipótese interpretativa, indagamo-nos se, por trás do exemplum amoroso que estaria no centro da composição, não haveria, também, um jogo mais sutil de contraste entre épica e elegia. Em suma, os elementos eróticos que encontramos na representação do cenário em Propércio I.20 mostram como no discurso elegíaco também a tópica do

thing, the correct term for water nymphs, Naiads, does not reproduce the upsilon-alpha sequence of Hylas as do Dryads and its variants. Of greater importance is the fact that the replacing of water nymphs by wood nymphs reinforces a punning etymological connection between Hylas and $v i \lambda \eta$ (or, in dialects other than Attic-Ionic, $v ं \lambda \alpha$ ), 'woods,' which his readers, knowing Greek, would have immediately appreciated". 
locus amoenus se submete ao tratamento típico desse gênero poético. Ao que saibamos, esse aspecto do poema não foi até o momento apontado pelos estudiosos.

\section{Referências}

ACHCAR, F. Lírica e lugar-comum: alguns temas de Horácio e sua presença em português. São Paulo: Edusp, 1994.

APOLONIO DE RODAS. Las Argonáuticas. Edición de Manuel Pérez Lópes. Madrid: Ediciones Akal, 1991.

BRYAN-BROWN, A. N. (org.). Oxford Latin Dictionary. Oxford: Oxford University Press, 1968.

CURRAN, L. C. Greek words and myth in Propertius 1.20. Greek, Roman and Byzantine Studies, Durham, vol. 5, p. 281-292, 1964.

CURTIUS, E. R. European Literature and the Latin Middle Ages. Princeton, N.J.: Princeton University Press, 1990.

FONSECA Jr., A. O. A Feácia de Homero e a constituição da tópica do "locus amoenus". 2012. 112 p. Relatório de Pesquisa (Iniciação científica desenvolvida na EFLCH/Unifesp, no Departamento de Letras, com bolsa FAPESP - processo $n^{\circ}$. 2010/10196-1). São Paulo: Escola de Filosofia, Letras e Ciências Humanas, Universidade Federal de São Paulo, 2012.

GRIMAL, P. Dicionário de mitologia grega e romana. Trad. Victor Jabouille. Rio de Janeiro: Bertrand Brasil, 2005.

HOMERO. Odisseia. Trad. Carlos Alberto Nunes. $2^{\mathrm{a}}$ ed. São Paulo: Ediouro, 2009.

HORÁCIO. Arte Poética. Trad. R. M. Rosado Fernandes. Lisboa: Inquérito, 1984.

OVID. Ovid in six volumes: vol. I. Edited by G. Showerman and G. P. Goold. Harvard: Harvard University Press, 1977.

OVÍDIO. Primeiro livro dos "Amores". Trad. Lucy Ana de Bem. São Paulo: Hedra, 2010.

PICHON, R. Index verborum amatoriorum. Hildesheim: Georg Olms Verlag, 1991.

PROPÉRCIO. Elegias de Sexto Propércio. Organização, trad., introdução e notas de Guilherme Gontijo Flores. Belo Horizonte: Autêntica, 2014. 
PROPERTIUS. Elegies I-IV. Edited, with introduction and commentary, by L. Richardson, Jr. Oklahoma: University of Oklahoma Press, 1977.

PROPERTIUS. Elegies: book I. Edited by W. A. Camps. Cambridge: Cambridge University Press, 1961.

PROPERTIUS. Elegies: book I. Text and translation with a critical analysis of each poem by R. I. V. Hodge and R. A. Buttimore. Bristol: Bristol Classical Press, 2002.

PROPERZIO, S. Il primo libro delle elegie. Introduzione, testo critico e commento a cura di P. Fedeli. Firenze: Leo S. Olschki Editore, 1980.

VIRGÍlIO. Bucólicas. Trad. e notas de Odorico Mendes, edição anotada e comentada pelo "Grupo de Trabalho Odorico Mendes". Cotia/ Campinas: Ateliê Editorial/ Editora da Unicamp, 2008.

VIRGÍLIO. Eneida. Trad. de J. V. Barreto Feio, J. M. da Costa e Silva. São Paulo: Martins Fontes, 2004. 